\title{
Advances and Perspectives in the Field of Auscultation, with a Special Focus on the Contribution of New Intelligent Communicating Stethoscope Systems in Clinical Practice, in Teaching and Telemedicine
}

\author{
Emmanuel Andrès
}

Additional information is available at the end of the chapter

http://dx.doi.org/10.5772/48402

\section{Introduction}

The stethoscope and the semantic of auscultatory findings were invented more than 200 years ago by Dr. Laennec (Traité de l'Auscultation Médiate, Paris, 1819 [Figure 1]) and over the years very few changes have been made to both the stethoscope itself and the way in which it is used [1]. However, the ability to differentiate between normal and abnormal sounds or noises (vesicular sounds, wheezes, crackles, etc) remains essential in clinical practice for correct diagnosis and management.

Over the past two decades, much of the progress made in this area has resulted primarily from improvements made to the stethoscope itself [1]. More recently, we have seen advances in the techniques used to process auscultatory signals as well as in the analysis and clarification of the resulting sounds [2,3]. The availability of novel representations of the sounds, with phono- and spectrograms, also opens interesting perspectives in the context of diagnostic aids, but also in education and pedagogy [4].

This chapter aims to review recent technological advances, evaluate promising innovations and perspectives in the field of auscultation, with a special focus on the development of new intelligent communicating stethoscope systems in clinical practice, and in the context of teaching and telemedicine. 


\section{Current semantic of auscultatory findings and characterization of sounds}

The physical characterization of physiological and pathological sounds in humans is still at a fledgling stage and has not yet resulted in reliable documentation, especially not so in the field of pulmonary auscultation [2]. In cardiology, the situation is somewhat similar. However, more precise data, essentially based on phonocardiography, are available, outdated as they may be [1]. Analysis and characterization of auscultation sounds have been totally neglected by practicing physicians and any major improvements have been made were primarily in auscultatory tools, i.e., the new intelligent communicating stethoscope systems [4].

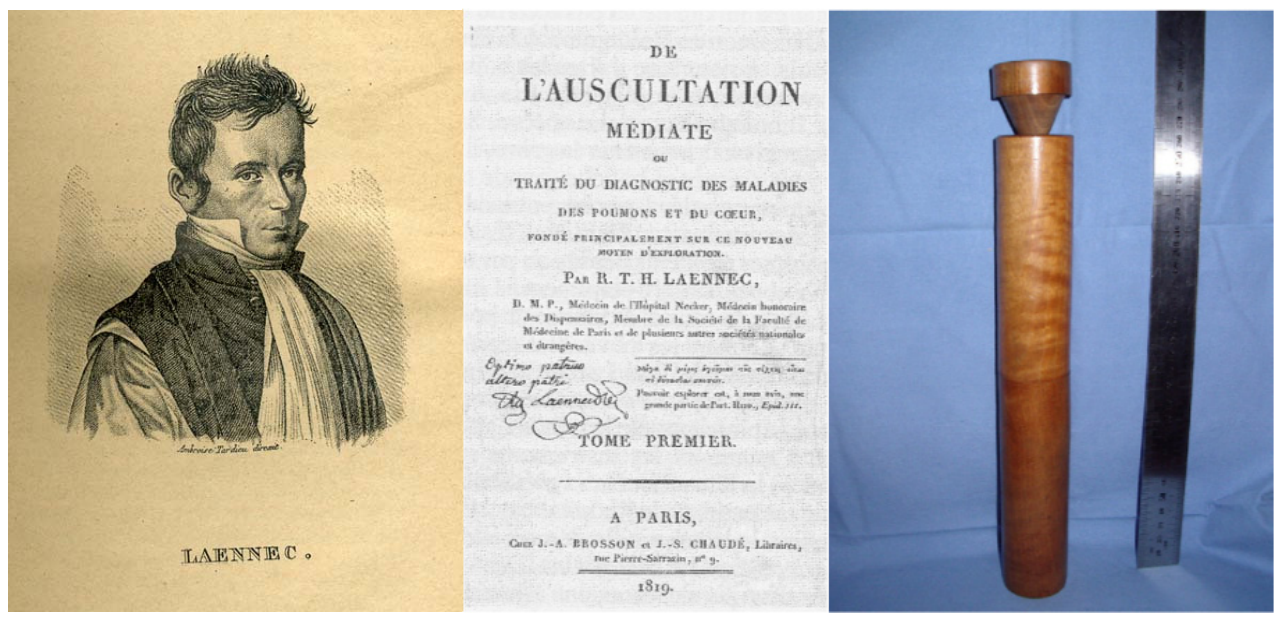

Figure 1. Portrait of René Théophile Hyacinthe Laennec. Front cover of the first edition of the "Traité de l'Auscultation Médiate", Paris, France, 1819. Note the handwritten Latin dedication to his uncle Guillaume Laennec in Nantes: "A mon excellent oncle, mon autre père" ("To my great uncle, my other father"). The original Laennec stethoscope, in wood, retains in the Museum of the History of Medicine, in Paris, France.

Whilst conventional stethoscope auscultation is subjective and hardly sharable, the characterization and identification of sounds by computer-based recording and analysis systems provide objective and early diagnostic help along with better sensitivity and reproducibility [2]. The precise definition of these physical characteristics and the availability of new visual representations of sounds constitute exciting perspectives for teaching and pedagogy, as we shall see later in this chapter [5].

Thus, as we have hypothesized, the new intelligent communicating stethoscope systems will also possibly contribute to a new auscultatory semiology, based on reliable methods of signal analysis and on visual display, and will be complementary to the acoustic signals perceived by the practitioner $[2,6]$.

Breath sounds or noises are produced by airflow in the respiratory system as well as the work of the breathing apparatus. These sounds are characterized by a wide spectrum of 
different sounds - the average frequency depends on the site of auscultation [3]. It is generally accepted that the frequency of lung sounds ranges between 50 and $2500 \mathrm{~Hz}$, while tracheal sounds can reach up to $4000 \mathrm{~Hz}[2,3,5]$. In terms of respiratory pathology, it should be emphasized that, only a small number of sounds are currently well identified and documented in regard of physical characteristics (for review see the reference [2]).

Table 1 gives a description of various auscultatory findings - normal breath sound, namely the vesicular murmur, and abnormal (pathological) - use clinically according to international literature [3,4].

\begin{tabular}{|c|c|c|}
\hline $\begin{array}{c}\text { Type of lung sounds } \\
\text { according to international } \\
\text { nomenclature }\end{array}$ & Clinical Features & Pathological circumstances \\
\hline Vesicular murmur & $\begin{array}{l}\text { Very soft noise, audible throughout } \\
\text { the entire phase of inspiration and } \\
\text { during early expiration. } \\
\text { Detected in antero-lateral areas of } \\
\text { the chest and in the back, it consists } \\
\text { in a continuous, soft low intensity } \\
\text { murmur, heard throughout } \\
\text { inspiration }\end{array}$ & $\begin{array}{l}\text { The vesicular murmur is weakened in the } \\
\text { following circumstances: } \\
\text { - extensive thickening of the wall, for example, } \\
\text { in obesity), for example, in cases of } \\
\text { emphysema (chest hyperinflation. } \\
\text { It is abolished when : } \\
\text { - the lung is collapsed by the pressure of fluid or } \\
\text { air in the pleural cavity, such as in cases of } \\
\text { pneumothorax or pleurisy } \\
\text { - absence of ventilation in the affected lung area, } \\
\text { for example, in cases of lung compression, } \\
\text { especially in atelectasis with retraction } \\
\text { - after pneumonectomy, on the operated side. }\end{array}$ \\
\hline Wheezes and whistles & $\begin{array}{l}\text { Of bronchial origin and variable } \\
\text { intensity, wheezes are heard at a } \\
\text { distance from the patient. } \\
\text { They include inspiratory wheezes, } \\
\text { as well as sibilant wheezes heard } \\
\text { during both phases of breathing. }\end{array}$ & $\begin{array}{l}\text { In cases of localized wheezing, it can be heard } \\
\text { during inspiration or during both phases, with } \\
\text { similar pitch, caused by partial obstruction of the } \\
\text { trachea or bronchi, due to the presence of a tumor } \\
\text { or foreign body. } \\
\text { In cases of diffuse wheezing, it is most often in the } \\
\text { form of bilateral wheezing, of various tonalities, } \\
\text { heard especially at the end of expiration and } \\
\text { encountered in instances of bronchial asthma. In } \\
\text { chronic obstructive bronchitis (bronchial } \\
\text { pneumonia), there is also diffuse expiratory } \\
\text { wheezing, due to vibration of the bronchial walls } \\
\text { which tend to collapse at expiration. }\end{array}$ \\
\hline Rhonchi or snoring & $\begin{array}{l}\text { Also of bronchial origin, sonorous } \\
\text { rhonchi are low-pitched, in both } \\
\text { inspiratory and expiratory phases, } \\
\text { and altered by coughing. }\end{array}$ & $\begin{array}{l}\text { They are encountered in acute or chronic } \\
\text { bronchitis accompanied with bronchial } \\
\text { hypersecretion. } \\
\text { Usually cleared by coughing, the so-called fixed } \\
\text { rhonchus on the other hand does not disappear } \\
\text { after coughing effort and is generally associated } \\
\text { with downstream bronchial obstruction. }\end{array}$ \\
\hline Coarse crackles (or rales) & $\begin{array}{l}\text { Also called mucous rales, bubbling } \\
\text { rales are discontinuous and of short } \\
\text { duration. Emitted sounds are } \\
\text { irregular, uneven, intense, observed } \\
\text { in both phases of respiration and } \\
\text { altered by coughing. }\end{array}$ & $\begin{array}{l}\text { They make a gurgling noise in the large airways } \\
\text { often associated with bronchial congestion due to } \\
\text { hypersecretion of mucus. They are predominantly } \\
\text { observed in bronchitis. }\end{array}$ \\
\hline
\end{tabular}




\begin{tabular}{|c|c|c|}
\hline $\begin{array}{c}\text { Type of lung sounds } \\
\text { according to international } \\
\text { nomenclature }\end{array}$ & Clinical Features & Pathological circumstances \\
\hline Fine crackles (or rales) & $\begin{array}{l}\text { Also called fine rales or crepitations, } \\
\text { they emit discontinuous, thin, dry } \\
\text { noises, high and evenly pitched, } \\
\text { occurring in spells during } \\
\text { inspiration. }\end{array}$ & $\begin{array}{l}\text { They become more distinctive after coughing and } \\
\text { usually point to an alveolar disease process. Due } \\
\text { to alveolar wall detachment and their pathological } \\
\text { features, they are observed primarily in cases of } \\
\text { pneumonia, interstitial alveolar or pulmonary } \\
\text { edema subsequent to heart failure, but also in } \\
\text { pulmonary fibrosis and in certain interstitial } \\
\text { pneumonias. }\end{array}$ \\
\hline $\begin{array}{l}\text { Bronchial or tubular } \\
\text { breathing } \\
\text { Bronchial sound }\end{array}$ & $\begin{array}{l}\text { A coarse, high intensity and high- } \\
\text { pitch noise that can be heard in both } \\
\text { inspiratory and expiratory phases, } \\
\text { although predominantly inspiratory. }\end{array}$ & $\begin{array}{l}\text { It can be heard over the thorax suggesting } \\
\text { pneumonia-induced pulmonary consolidation } \\
\text { and is typically accompanied by a series of } \\
\text { crackles }\end{array}$ \\
\hline Pleural breathing sound & $\begin{array}{l}\text { A soft, distant, veiled expiratory } \\
\text { sound. }\end{array}$ & $\begin{array}{l}\text { It is heard at the upper limit of moderate pleural } \\
\text { effusion. Like (bronchial or tubular) breathing, it } \\
\text { is determined by pulmonary consolidation } \\
\text { complicated by pleurisy. Although attenuated by } \\
\text { the latter, it nevertheless exhibits different } \\
\text { features than (bronchial, tubular) breathing. }\end{array}$ \\
\hline Amphoric breathing & $\begin{array}{l}\text { A high-pitch expiratory metallic } \\
\text { sound }\end{array}$ & $\begin{array}{l}\text { It is caused by the resonance of normal breath } \\
\text { sounds in an air pocket, for example in cases of } \\
\text { pneumothorax (with a persistent pleural breach). }\end{array}$ \\
\hline $\begin{array}{l}\text { Pleural rub or Pleural } \\
\text { friction rub }\end{array}$ & $\begin{array}{l}\text { Dry grating and superficial sounds, } \\
\text { unchanged by coughing. Their } \\
\text { Intensity may be discrete, like the } \\
\text { «rustle of silk paper», or intense, } \\
\text { such as the «creaking sound of new } \\
\text { leather». }\end{array}$ & $\begin{array}{l}\text { They are due to the two inflamed pleural layers } \\
\text { rubbing against each other. They occur at the } \\
\text { onset of pleurisy, at its upper limit or after fluid } \\
\text { evacuation. } \\
\text { The differential diagnosis with that of coarse } \\
\text { crackles may be difficult, but unlike the latter, } \\
\text { pleural rubs appear soon after the start of } \\
\text { inspiration. }\end{array}$ \\
\hline
\end{tabular}

Table 1. International semantic on normal and abnormal lung sounds use in clinical practice $[2,7,8]$.

The generation of heart sounds is essentially related to cardiac muscle contraction, the functioning of the valves and turbulence generated by blood flow. The spectrum of heart sounds is between 20 and $100 \mathrm{~Hz}$ for baseline signals and higher frequencies for murmurs: $500 \mathrm{~Hz}$ and above [1,2]. S1, corresponding to the closure of the mitral and tricuspid valves, incorporate frequencies ranging from 10 to $100 \mathrm{~Hz}$. S2, resulting from the opening of the aortic and pulmonary sigmoid valves, is of higher frequency, generally between 150 and 200 Hz. It should be noted that additional heart sounds (S3 and S4) may be heard and additional diastolic noises originating from the valves can also be observed with mitral opening snap, pericardial (friction) rub or knock, etc. Lastly, we can also detect so-called "organic murmurs" which are related to alterations of the mitral or tricuspid atrioventricular valves (inlet valves) or ventriculo-aortic or pulmonary valves (ejection valves) (for review see the reference [4]).

Figure 2 depicts the chronological and morphological characteristics of heart murmurs, illustrating how the practitioner makes a diagnosis by taking into account these elements when analyzing the auscultatory signal perceived [2]. 
Systolic murmurs
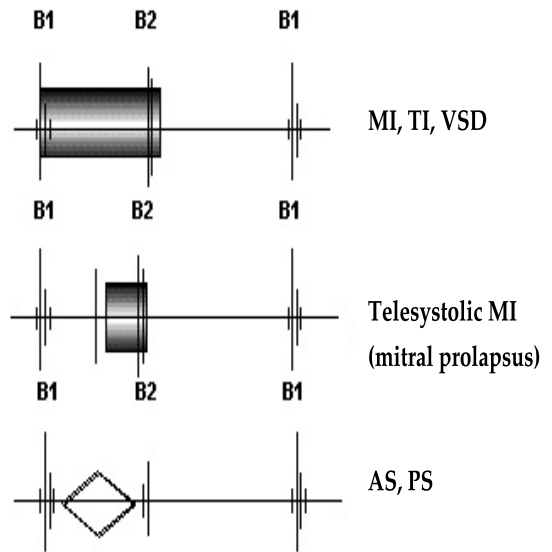

AS, PS

Distolic murmurs

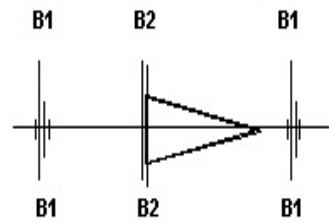

AI, PI

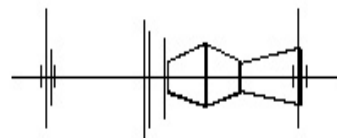

MS, TS

Continuous murmur

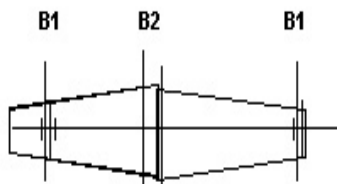

Patent ductus arteriosus

AS : aortic stenosis; AI : aortic insufficiency; PS : pulmonary stenosis; PI : pulmonary insufficiency; MS : mitral stenosis; MI : mitral insufficiency; TI: tricuspid insufficiency; TS : tricuspid stenosis; VSD : ventricular septal defect.

Figure 2. Schematic representation of breaths during the cardiac cycle.

\section{Advances and perspectives in documentation and characterization of sounds}

In practice, auscultation diagnoses are often made based solely on past experience of the practitioners, and rely more on intuition than on rigorous and systematic classification 
systems [1]. However in recent years, various studies have endeavored to characterize, identify and describe sounds in greater detail, especially in the respiratory field [5-8].

It is in this context that an innovative project known as ASAP: "Analyse de Sons Auscultatoires et Pathologiques" (Analysis of Auscultatory and Pathological Sounds) was developed by the French national agency for research (ANR 2006 - TLOG 21 04, headed by Professor E. Andrès) [5]. This project was supported by the development and the provision of a new intelligent communicating stethoscope system.

The main objective of this project was to bring pulmonary auscultation into the era of evidence-based medicine, based on the identification of sounds using innovations in technology, mathematics and computer science in order to "rediscover" the clinical significance of respiratory sounds [5]. The ASAP project allowed us to documented physically characterized these sounds in more detail.

To date, we have collected over 500 auscultations, well-documented clinically (Figure 3), and began an analysis of its physical characteristics of the sounds. Thus, physicallyspeaking, crackles correspond to a characteristic wave whose appearance is shown in Figure 4, a representation revisited and detailed elsewhere [4,9]. Note that it is generally accepted that the duration of crackles is less than $20 \mathrm{~ms}$ and their frequency is between 100 and 200 $\mathrm{Hz}$ [10]. A sibilant wheeze, on the other hand, is characterized by a waveform with a

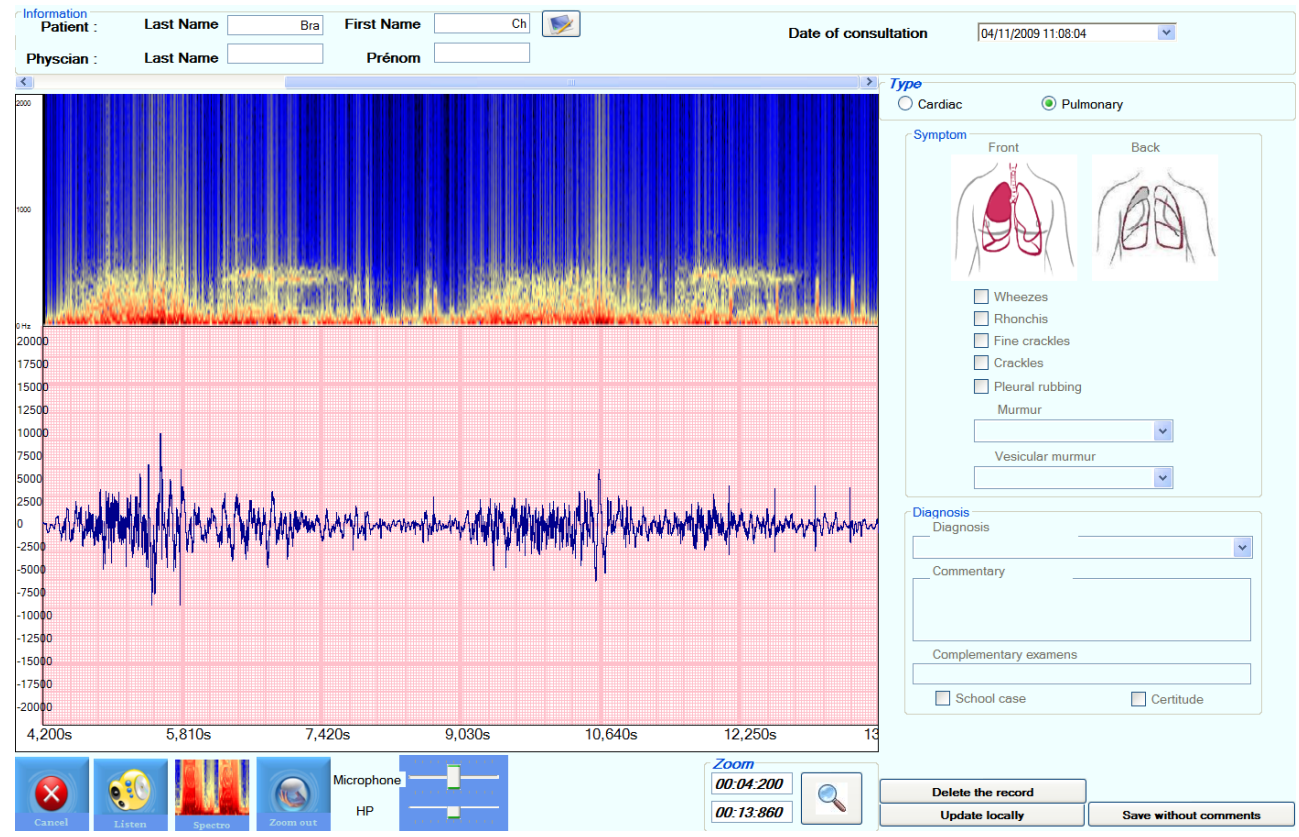

Figure 3. Clinical documentation and physical characterization of sounds collected through the ASAP project. These data includes: characteristics of the patient; auscultation type; acoustic data; diagnosis; sounds (data collected in the ASAP project) [5]. 
Advances and Perspectives in the Field of Auscultation, with a Special Focus on the Contribution of New Intelligent Communicating Stethoscope Systems in Clinical Practice, in Teaching and Telemedicine

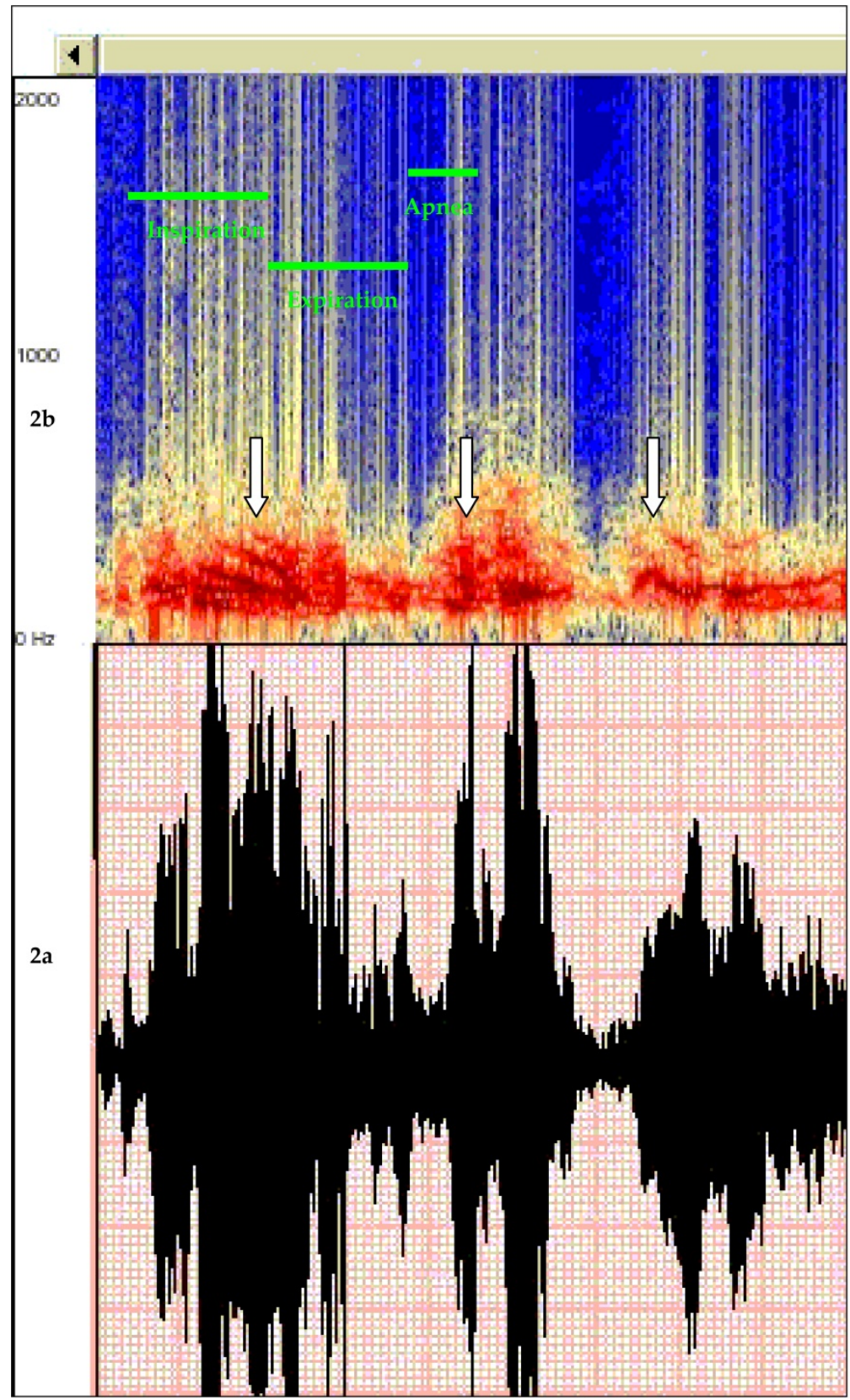

Figure 4. Representation of a breathing cycle in a patient with chronic obstructive pulmonary disease, along with respective phases of inspiration, expiration and respiratory pause in the form of a phonopneumogram (2a) and a spectrogram (2b). Presence of numerous coarse crackles especially visible on the spectrogram (2b) (indicated by arrows) (data collected in the ASAP project) [5]. 
dominant frequency usually above $100 \mathrm{~Hz}$ and a duration exceeding $100 \mathrm{~ms}$. In terms of physics, wheezing sounds are longer than 50 or $100 \mathrm{~ms}$ but less than $250 \mathrm{~ms}[4,9,10]$. The frequency of wheezes ranges between 100 and $2500 \mathrm{~Hz}$ with a characteristic peak frequency of 100 or $400 \mathrm{~Hz}$ and 1000 or $1600 \mathrm{~Hz}$.

The ASAP project is complementary to other work conducted locally at the University Hospital (CHRU) of Strasbourg in collaboration with the research team led by Doctor C. Brandt, notably the project: "Perspectives et apports $d u$ développement d'un stéthoscope communiquant à l'ère de la telemedicine" (Perspectives and contributions of the development of a communicating stethoscope in the era of telemedicine) (PRI HUS - No. 4179, headed by Doctor C. Brandt and Professor E. Andrès, Strasbourg, France) [6].

The objectives of this project were: validation of a new communicating stethoscope we have developed (see a next section of this chapter); comparison of conventional (acoustic) auscultation with this new communicating stethoscope system; creating an auscultatory library; and development of expert systems for real-time analysis of signals from cardiovascular and pulmonary auscultation for diagnosis assistance.

Forward, the ASAP and PRI projects aims at making evolve the auscultation technics:

- first, by the development objective tools for the analyse of auscultation sounds: electronic stethoscopes paired with computing device;

- by the creation of an auscultation sounds' database in order to compare and identify the physical characteristics, the acoustical and visual signatures of the pathologies;

- and lastly, by the capitalisation of these new auscultation techniques around the creation of a teaching unit and a school of auscultation on the web (http://www.websound.fr) [5,6]. This auscultation's school, potentially hosted on the web, will be destined to the initial and continuous formation of the medical attendants (Figure 5).

\section{Advances in the field of sound representation and perspectives in teaching}

Whereas conventional auscultation is subjective and interpreted by a single clinician, the characterization of sounds through recording, analysis and auscultatory signal processing systems provides in several studies better sensitivity and specificity when interpreting findings $[4,11]$. The availability of new technologies opens up interesting perspectives in the field of diagnostic tools, but also in education [4,12].

In fact, as well as providing a reliable addition to routine clinical diagnosis, these "tools" should ultimately lead to improvements in auscultatory training, based on the "physical" characterization of signals and sounds, as well as a visual representation in the form of:

- phonopneumogram or phonocardiogram: a tool providing simultaneous representation in time of the respiratory phases (Figure 2a) or the cardiac cycle and the auscultation signal (Figure 6a); 
- spectrogram: a tool where time is indicated on the abscissa, frequency on the ordinate and the intensity of the signal is represented by a color palette for the respiratory (Figure $2 b$ ) or heart signal (Figure $6 \mathbf{b}$ ).

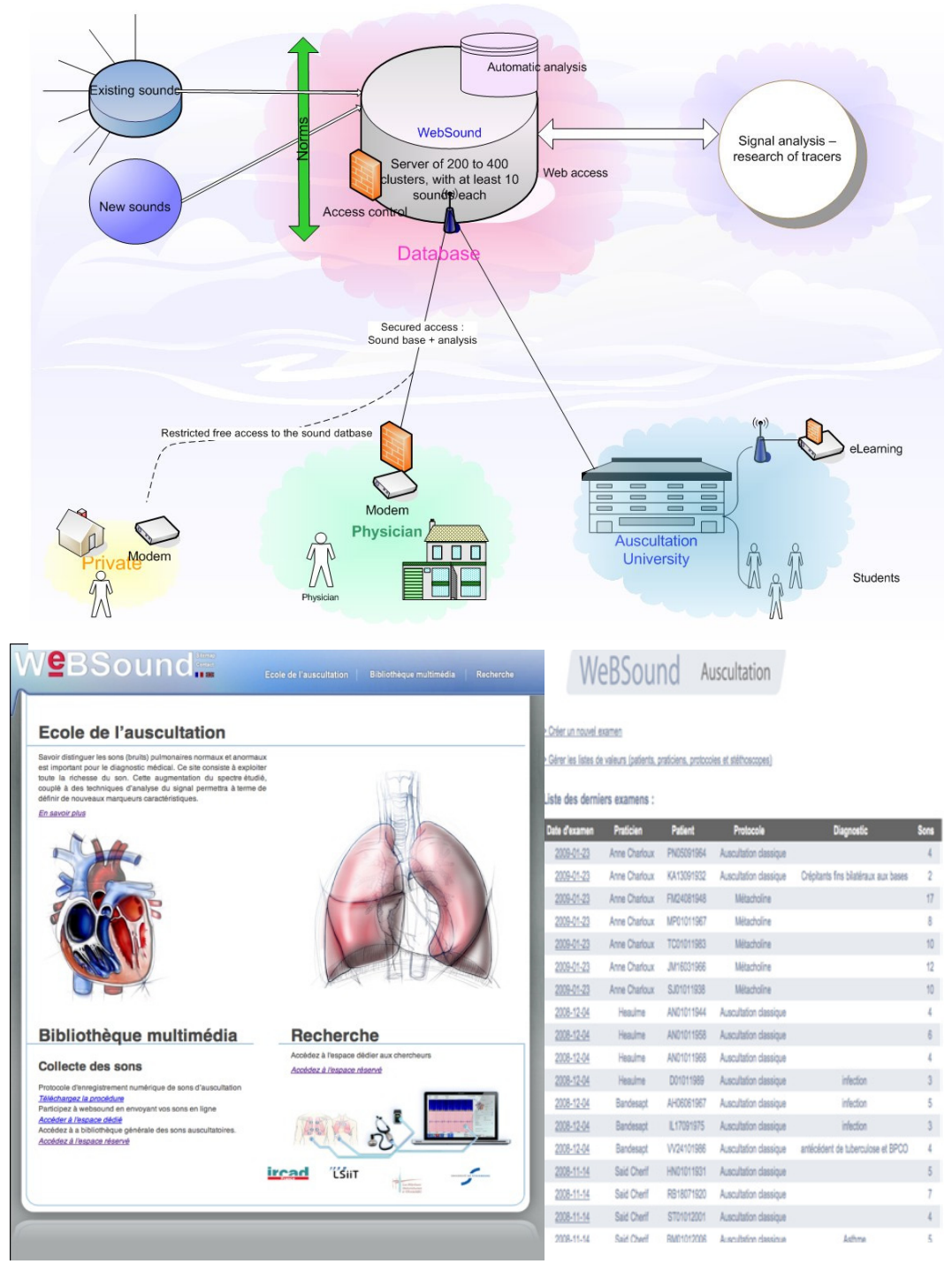

Figure 5. Potential teaching contributions of advances and innovations in the field of auscultation with the creation of a school of auscultation on the web [4,5]. This school of auscultation includes several components: Patient follow-up, Collection of sounds, Consultation, Transmission, Listening, Analysis, Validated and classified respiratory sounds, Automated analysis, Sound database, Secured access, Students, Initial training, School of Auscultation, Physicians, Diagnostic aid, Continuing Education, Specialists, Certification Validation. 


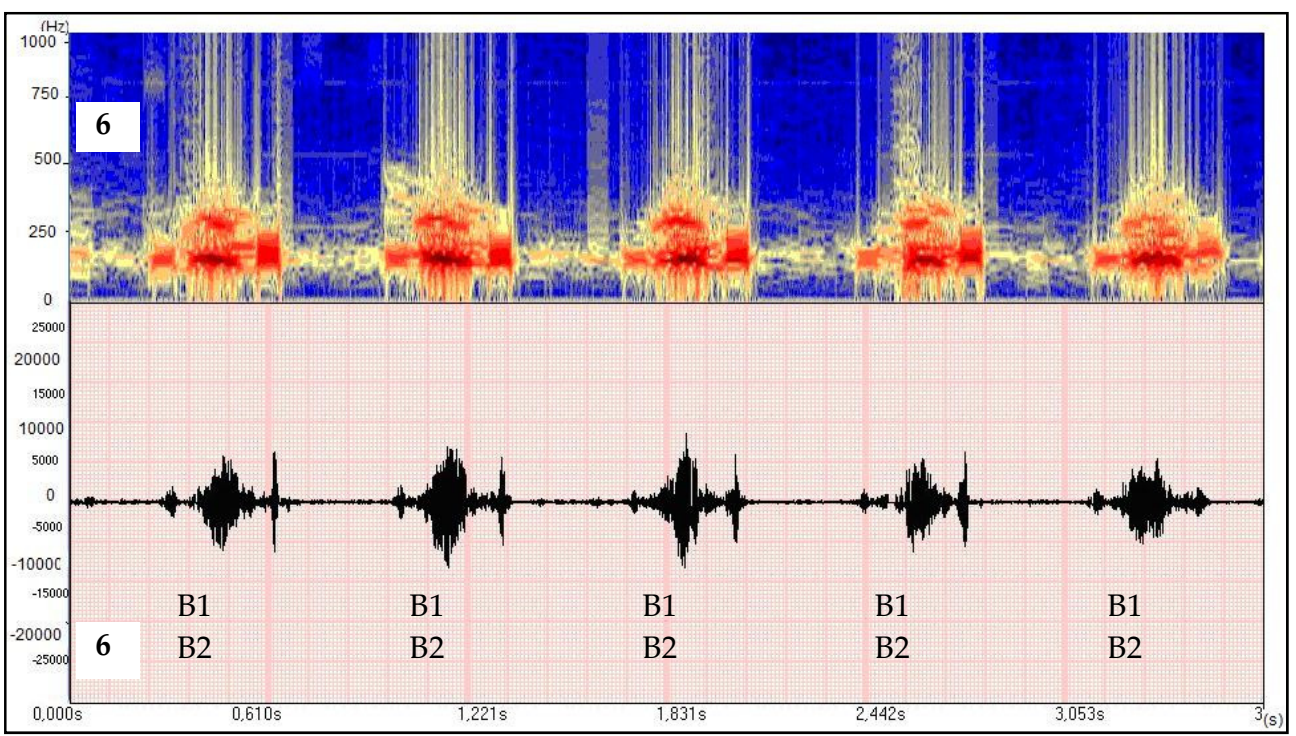

Figure 6. Representation of a recording of a cardiac auscultation in an individual with aortic stenosis with a systolic ejection murmur (indicated by a white arrow) in the form of a phonocardiogram (6a) and a spectrogram (6b) (data collected in the PRI project) [4,5].

To have a sort of proof of concept of the "plus value" of our intelligent communicating stethoscope system, we conducted a preliminary study at the University Hospital of Strasbourg with the aim of evaluating the diagnostic "performance" of these new visualization tools (phono- and spectrogram). We asked a cohort of medical graduate students $(n=30)$ to listen to 10 sounds in order to diagnose heart and lung pathology [13].

They were then asked to tick the appropriate box corresponding to the diagnosis relating to the sound they had just heard (as with an acoustic stethoscope). The correct response rate was 40 to $60 \%$. The same exercise was then carried out again with the addition of a visual representation of the sound (phonopneumogram or phonocardiogram and spectrograms). In this second phase of the trial, the rate of correct diagnosis reached 70 to $90 \%$. Table 2 presents the detail of these data. Analysis of this table shows that the improved performance (rate of correct diagnosis) is particularly significant for cardiac pathology.

Thus in our experience, addition of visual representation of sounds has significant implications in terms of medical medical education, and also in term of decision-making, potential patient safety, and cost control. In the field of teaching, a recent well designed study conducted by Sestini et al. supports the results of our work, concluding that an association between the acoustic signal and the image is highly useful for learning and understanding the basis of respiratory sounds [12].

To date, several stethoscopes on the market are already accompanied by specialized software providing the physician with a "visual representation of sounds", using various time-frequency representations, in the form of images. These can then be used in 
conjunction with the auditory information obtained from a stethoscope to achieve a diagnosis [6]. This "second channel" of information allows the practitioner to strengthen his clinical findings, and is likely to result in a more reliable diagnosis [14]. Figure 7 illustrates this concept by using the example of aortic insufficiency (confirmed by cardiac ultrasound scan) which was not heard with the acoustic stethoscope but was visualized using our intelligent stethoscope prototype from the ASAP project [4]. This is a major achievement, using advances in medical technology to facilitate the work and training of practitioners.
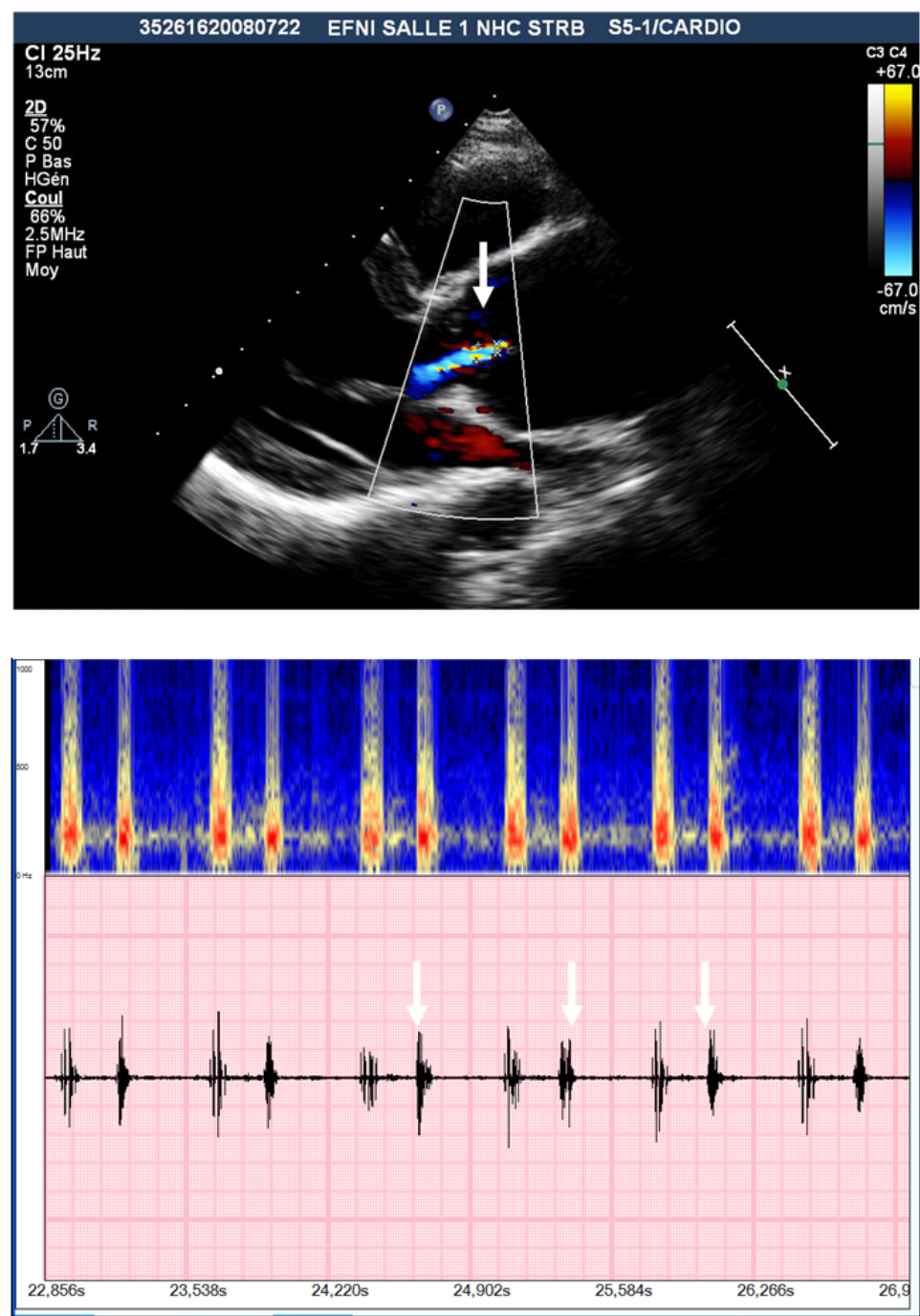

Figure 7. Aortic insufficiency (indicated by white arrows) not heard with the acoustic stethoscope but visualized using our intelligent stethoscope prototype and confirmed by echocardiography (data collected in the ASAP project) [4]. 


\begin{tabular}{|c|c|c|}
\hline & \multicolumn{2}{|c|}{$\begin{array}{l}\text { All students } \\
\quad(\mathrm{n}=30)\end{array}$} \\
\hline & Without tools & With tools \\
\hline$\%$ of "good" diagnosis $(n=10)$ & $64 \%(191)$ & $80 \%(239)$ \\
\hline $\begin{array}{l}\text { \% of "good" diagnosis in respiratory auscultation }(\mathrm{n}=5) \text { : } \\
\text { normal respiratory auscultation } \\
\text { crackles (chronic bronchitis) } \\
\text { crackles (interstitial pneumonia) } \\
\text { wheeze sibilants (acute crisis of asthma) } \\
\text { stridor (lung carcinoma) }\end{array}$ & $\begin{array}{l}61 \%(92) \\
57 \%(17) \\
57 \%(17) \\
53 \%(16) \\
70 \%(21) \\
70 \%(21)\end{array}$ & $\begin{array}{l}70 \%(105) \\
63 \%(19) \\
60 \%(18) \\
70 \%(21) \\
83 \%(25) \\
73 \%(22)\end{array}$ \\
\hline $\begin{array}{l}\text { \% of "good" diagnosis in cardiac auscultation }(\mathrm{n}=5) \text { : } \\
\text { normal cardiac auscultation } \\
\text { aortic stenosis } \\
\text { aortic regurgitation (minimal murmur) } \\
\text { mitral stenosis } \\
\text { arrhythmia (auricular fibrillation) }\end{array}$ & $\begin{array}{l}66 \%(99) \\
73 \%(22) \\
60 \%(18) \\
30 \%(30) \\
40 \%(12) \\
57 \%(17)\end{array}$ & $\begin{array}{l}89 \%(134) \\
93 \%(28) \\
100 \%(30) \\
70 \%(21) \\
87 \%(26) \\
97 \%(29)\end{array}$ \\
\hline
\end{tabular}

Table 2. Results of the use of new tools as phono- and spectrogram for visualizing sounds in 30 medical students [13].

\section{Advances and innovations in the field of auscultatory signal analysis}

To date, there has been very little research on the analysis of auscultatory signals. In terms of signal automation and processing, research is limited to detection of frequency peaks, sound duration measurements, etc $[15,16]$.

In cardiology, little work has been conducted to render the stethoscope "intelligent" by allowing it to provide the clinician with an advanced diagnostic tool, as, for example, that provided by ECG systems which offer the practitioner a plot analysis as a diagnostic aid $[14,17]$.

Of note is the work by Mint and Dillard who developed a stethoscope capable of diagnosing systolic or diastolic sounds present between B1 and B2 beats, and which measured the heart rate using a simple time-frequency analysis of the time periods of interest [14].

We also should acknowledge the work carried out by Murphy, who worked towards developing an "intelligent" stethoscope for which the technology is both interesting and innovative. These studies are reviewed, appended and presented in detail in reference [2].

In terms of respiratory medicine, the automated analysis of pulmonary auscultatory signals remains a challenge, especially compared with the cardiac field. The European Communityfunded CORSA project, conducted between 1990 and 2000, provides an overview of the technical advances in respiratory sound analysis using signal processing tools $[8,18]$.

Several studies have also provided an update on the various techniques used for the capture and digitization of respiratory sounds as well as giving an overview of analytical methods 
based on more standardized semantics [17-20]. A summary of the techniques and characteristics of the leading methods used to assess each type of respiratory sound is provided in references [2,16,17].

As part of the ASAP project mentioned above [5], the team led by Professor C. Collet of the Image Sciences, Computer Sciences and Remote Sensing Laboratory (LSIIT) of the University of Strasbourg (in Strasbourg, France), developed a novel approach in automated analysis of pulmonary auscultation signals [20-22]. As a second step, we then validated this approach on a small number of patients presenting with either: an auscultation defined as "normal", COPD with numerous crackles or asthma with wheezing.

The methods developed by C. Collet's team involve multiresolution signal analysis through the use of Bayesian tools in the wavelet packet domain, associated with multimodal Markovian modeling adapted for the analysis of lung sounds (high intra and interpatient variability, low signal to noise ratio SNR) (http://lsiit-miv.u-strasbg.fr/lsiit/perso/collet/) [21,22]. Innovative vagueness (fuzzy) and uncertainty (probability) concepts on the observed data were developed and implemented successfully and resulted in the defining of an early statistical marker of asthma. These studies also focused on the detection of crackles using a deconvolution method (Bernoulli Gaussian model) allowing the density of the crackles to be quantified [4].

It should be mentioned that, in collaboration with the team led by Professor A. Dieterlen (University of Haute Alsace, Mulhouse, France), our team at the University Hospital of Strasbourg are also trialing a complementary approach in the field of cardiac signal analysis (PRI project [see above]).

Ultimately, there is scope for these different innovations to be combined in the future after refining and re-valuation of the procedures involved (using strict protocols similar to those used for drug development), to create new "communicating," "intelligent" stethoscopes.

\section{Advances and innovations in the realm of the stethoscope}

Today's technology, along with developments in modern medicine means that in the near future a communicating, wireless stethoscope will soon become available. This stethoscope will enable the recording, automated analysis and visualization of auscultatory signals $[6,9]$.

INFRAL, a company (with whom we collaborate) based in Strasbourg, France, has developed several prototypes, with the aim of creating an intelligent communicating stethoscope system, which combines a diagnostic aid with tools for visualization and automated analysis [4].

This diagnostic aid is not only a helpful tool which assists physicians in making rapid decisions, but it will also allow developments in the field of telemedicine, for example; by the establishment of a database of auscultation sounds, by enabling the exchange of sounds between physicians and by allowing auscultation to be performed "from a distance" e.g. when seeking further expertise, etc. More importantly, it will allow auscultation to enter the field of fact-based medicine [6,9]. 
Figure 8 depicts one of the intelligent stethoscope prototypes, which uses Bluetooth to communicate with a PC, hand held computer or smartphone. This prototype was developed initially in the ASAP project (input of ALCATEL LUCENT), than by INFRAL, combining our expertise from several research projects as well as in the field of human sounds analysis, electronic stethoscope, e-health, e-teaching [4].

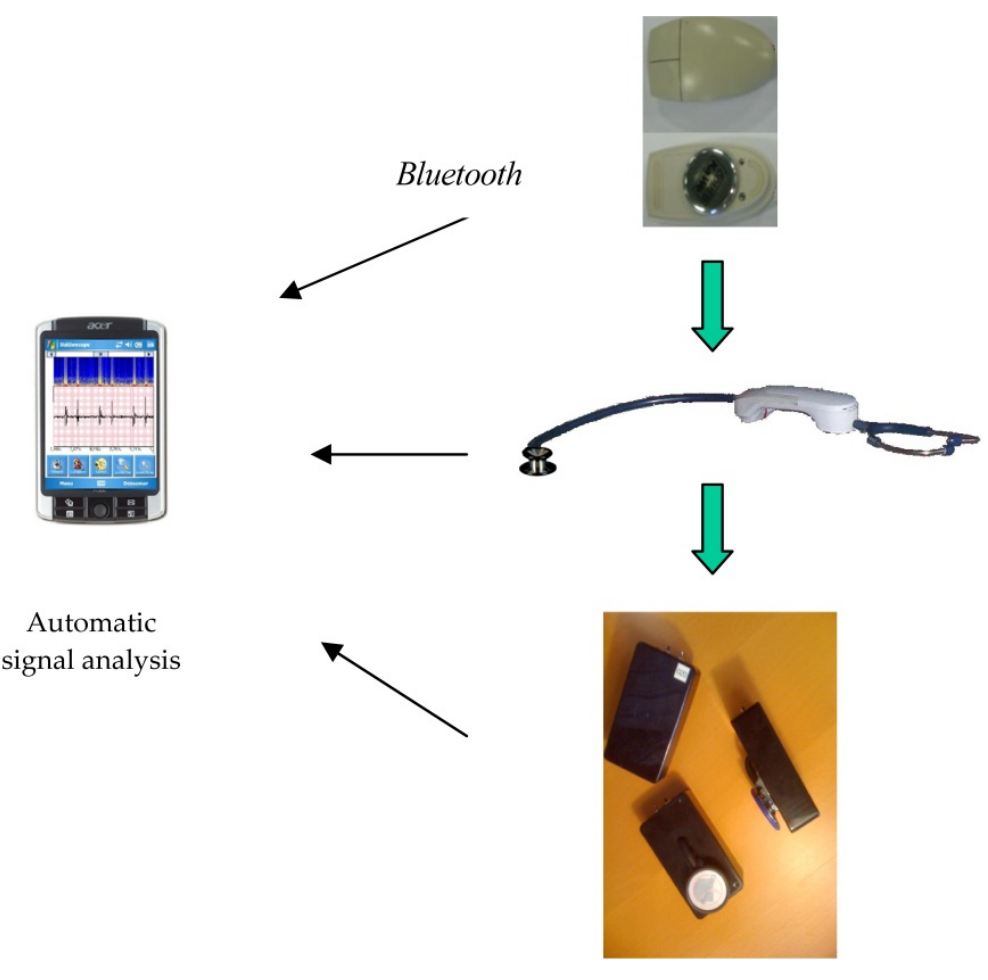

Figure 8. Several prototypes of intelligent (automatic signal analysis) communicating (Bluetooth) stethoscope system developed by our team in Strasbourg, France in different research projects, in collaboration mainly with LANNEXT, ALCATEL LUCENT, and currently with INFRAL [4].

In practical terms, a certain number of modern stethoscope models already feature functions for recording, storing and transmitting sounds. Table 3 presents an overview of the major "electronic" stethoscope models currently available on the market and those, which we have tested $[4,23]$. The following section outlines two examples of new intelligent communicating stethoscope systems that we tested in clinical practice in our Department. 


\begin{tabular}{|c|c|c|c|c|c|}
\hline & $\begin{array}{c}\text { Frequency bands } \\
\text { and implemented } \\
\text { filters }\end{array}$ & $\begin{array}{l}\text { Communication } \\
\text { mode }\end{array}$ & $\begin{array}{l}\text { Additional } \\
\text { Information }\end{array}$ & Ref & Price \\
\hline Andromed & $\begin{array}{l}\text { Presence of filers } \\
\text { (high-pass at } 200 \\
\mathrm{~Hz} \text { ) }\end{array}$ & Wired connection & & $\begin{array}{l}\text { [Andromed 08a] } \\
\text { [Andromed 08b] }\end{array}$ & \\
\hline Jabes & $\begin{array}{l}\text { Diaphragm mode } \\
\text { (lung): } 200 \text { to } 500 \\
\text { Hz } \\
\text { Bell mode (heart) : } \\
20 \text { to } 200 \mathrm{~Hz} \\
\text { Wide mode : } 20 \text { to } \\
1000 \mathrm{~Hz}\end{array}$ & Wired connection & & [Jabes 08] & $\$ 299-\$ 389$ \\
\hline Stethoflux & & & \begin{tabular}{|l|} 
Coupling of \\
acoustic \\
stethoscope and \\
integrated \\
continuous \\
wave doppler \\
\end{tabular} & [Stethoflux 08] & $\$ 960$ \\
\hline Welch-Allyn & $\begin{array}{l}20 \text { - } 20000 \text { Hertz ; } \\
\text { although two } \\
\text { modes are } \\
\text { present : the bell } \\
\text { mode (heart) } 20- \\
420 \mathrm{~Hz} \text {, and the } \\
\text { diaphragm mode } \\
\text { (lungs) 350-1900 } \\
\mathrm{Hz}\end{array}$ & Wired connection & Integrated ECG & [WelchAllyn 08] & $\$ 225-\$ 240$ \\
\hline 3M Littmann & $\begin{array}{l}\text { Bell mode }(20-200 \\
\text { Hz), diaphragm } \\
\text { mode }(100-500 \\
\text { Hz) and extended } \\
\text { mode (20-1000 } \\
\text { Hz). }\end{array}$ & Infrared & $\begin{array}{l}\text { Transfer and } \\
\text { display of } \\
\text { sounds require } \\
\text { additional time } \\
\text { and investment } \\
\text { by the physician } \\
\text { conducting the } \\
\text { auscultation } \\
\text { Differed } \\
\text { viewing and not } \\
\text { in real time } \\
\end{array}$ & [Littmann 08] & $\begin{array}{c}\$ 465-\$ 674 \\
(4100 W S \\
\text { model })\end{array}$ \\
\hline Thinklabs & $\begin{array}{l}\text { Filter for adjusting } \\
\text { sound in } \\
\text { bell/diaphragm } \\
\text { mode, and } \\
\text { acoustic mode. }\end{array}$ & & $\begin{array}{l}\text { Analysis } \\
\text { software } \\
\text { derived from } \\
\text { Audacity }\end{array}$ & [Thinklabs 08] & $\$ 400-\$ 500$ \\
\hline Cardionics & $\begin{array}{l}8 \text { filters enabling } \\
\text { the attenuation or } \\
\text { amplification of } 8 \\
\text { different } \\
\text { frequency bands }\end{array}$ & Wired (jack) & $\begin{array}{l}\text { Also has a } \\
\text { complement } \\
\text { system enabling } \\
\text { ECG capability }\end{array}$ & $\begin{array}{c}\text { [Cardionics } \\
\text { O8a][Cardionics } \\
\text { O8b] }\end{array}$ & $\$ 335$ - \$575 \\
\hline
\end{tabular}




\begin{tabular}{|l|l|l|l|l|l|}
\hline & $\begin{array}{c}\text { Frequency bands } \\
\text { and implemented } \\
\text { filters }\end{array}$ & $\begin{array}{c}\text { Communication } \\
\text { mode }\end{array}$ & $\begin{array}{c}\text { Additional } \\
\text { Information }\end{array}$ & Ref & Price \\
\hline $\begin{array}{l}\text { Cardionics - } \\
\text { Stethographics }\end{array}$ & $\begin{array}{l}8 \text { filters enabling } \\
\text { the attenuation or } \\
\text { amplification of } 8 \\
\text { different } \\
\text { frequency bands }\end{array}$ & Wire (jack) & Multi probes & [Stethographics 08] & $\$ 279-\$ 489$ \\
\hline
\end{tabular}

Table 3. Principal characteristics of electronic stethoscopes currently available commercially [4].

The JABES Life Sound System is an auscultatory system composed of the JABES Electronic Stethoscope and JABES Life Sound Analyzer software. JABES hold the patent to this stethoscope technology, which consists primarily of an analog amplifier that can amplify body sounds up to 20 times. Hand tremor and ambient noise is minimized using information provided by the manufacturer, but in reality noise from the chest piece is very important.

The stethoscope offers various modes of auscultation: Bell, Diaphragm or Wide, each with 7 levels of volume control. Auscultation modes are reported to imitate the behavior of an acoustic stethoscope. Moreover, the system includes filters that reject certain frequency ranges in order to focus on lung or heart signals.

The JABES Life Sound System software allows the physician to record the body sounds of the patient directly onto his PC in order to view the phonocardiogram. In addition, heart and lungs sounds as well as the heartbeat can be visualized in real time.

The connection between the stethoscope and the PC or external recording equipment comprises a cable connected to the PC or external recorder jack socket. Sounds can be recorded on the PC in MP3 format, but are not documented. In particular, the sample sounds are not accompanied by tags (i.e. basic information such as the area over which the sample was taken).

It is also significant that sounds cannot be transmitted in "real-time" - hence simultaneous auscultation from a distance is not possible: the signal must first be recorded on the PC, before it can be transferred via email, CD or USB flash drive (for a second opinion). Thus because of these limitations, in our opinion it is not suitable for teaching purposes.

The $3 \mathrm{M}^{\mathrm{TM}}$ LITTMANN stethoscope (LITTMANN 08) is an electronic stethoscope that allows to 6 different sound recordings during auscultation. The sounds are stored directly in .wav format in the internal memory of the stethoscope.

The practitioner can then, through an analog connection to the PC (i.e. external microphone jack), or via an infrared link, transfer the sounds onto his PC for viewing using specific software provided by $3 \mathrm{M}$.

This stethoscope allows sound to be amplified up to 18 times. It has several features including: ambient mechanical noise reduction technology, configurable filters with 3 frequency response modes for listening to the heart, lungs and other human body sounds: bell mode (20-200 Hz), diaphragm mode (100-500 Hz) and extended mode (20-1000 Hz). 
The features are very similar to those of the JABES stethoscope; however this system is much more expensive. The stethoscope allows the physician to view the auscultatory sounds; although the display image is delayed and not in real time. Moreover, the transfer of sounds and their display require both additional cost and time. During auscultation it is not possible to visualize how the frequency spectrum of the signal changes with time, making the examination unsystematic, complicated, and invariably much longer.

It should be noted that the electronic stethoscopes currently on the market all have analog amplifiers, providing the option of connecting to a PC through the analog microphone jack socket [4]. In order to simulate "defects" introduced by acoustic stethoscopes, these electronic stethoscopes all offer analog filters that supposedly mimic the behavior of the bell or chest piece of the acoustic stethoscope. Finally, the wired connection between the stethoscope and the storage/processing device (PC or hand held computer or smartphone) is a major handicap in terms of user ergonomics.

\section{Perspectives for the use of the new intelligent communicating stethoscope system in telemedicine in the field of chronic pathologies}

Moreover, applications, including diagnosis establishment, monitoring and data exchange through Internet are obviously complementary tools to objective and automatic auscultation sounds analysis. Sensors devices will allow long duration monitoring for patient at home or at hospital. It could also be a useful solution for less-developed countries and remote communities... In addition, this type of system has the great advantage to keep the noninvasive and less expensive characteristics of auscultation.

The European based project, known as E-PERION, aims to develop telemedicine by using a platform which enables "secure" home support for fragile patients and/or those with chronic diseases (LEAD-ERA tender, 2010) (Figure 9). An intelligent communicating stethoscope system is one the deployed devices, especially in patients with respiratory and/or cardiac failure. This project is developped by INFRAL company (based in Strasbourg, France), in association with our team in Strasbourg.

This company is actively involved in the design and manufacture of modular and portable devices, which enable the transfer of essential medical data (http://infral-systems.com/). Such devices use innovative concepts to register and transmit vital parameters from medical devices.

In clinical practice, the most interesting and immediate advantages offered by this tool include:

- the ability to strengthen clinical evidence in favor of a particular diagnosis by visualization of the acoustic "pattern" of the sound;

- the ability to monitor the evolution of a pathology, by recording findings in a given individual;

- and the ability to share data, allowing the exchange of data between health care professionals (using an infrastructure similar to that of the ASAP project)). 


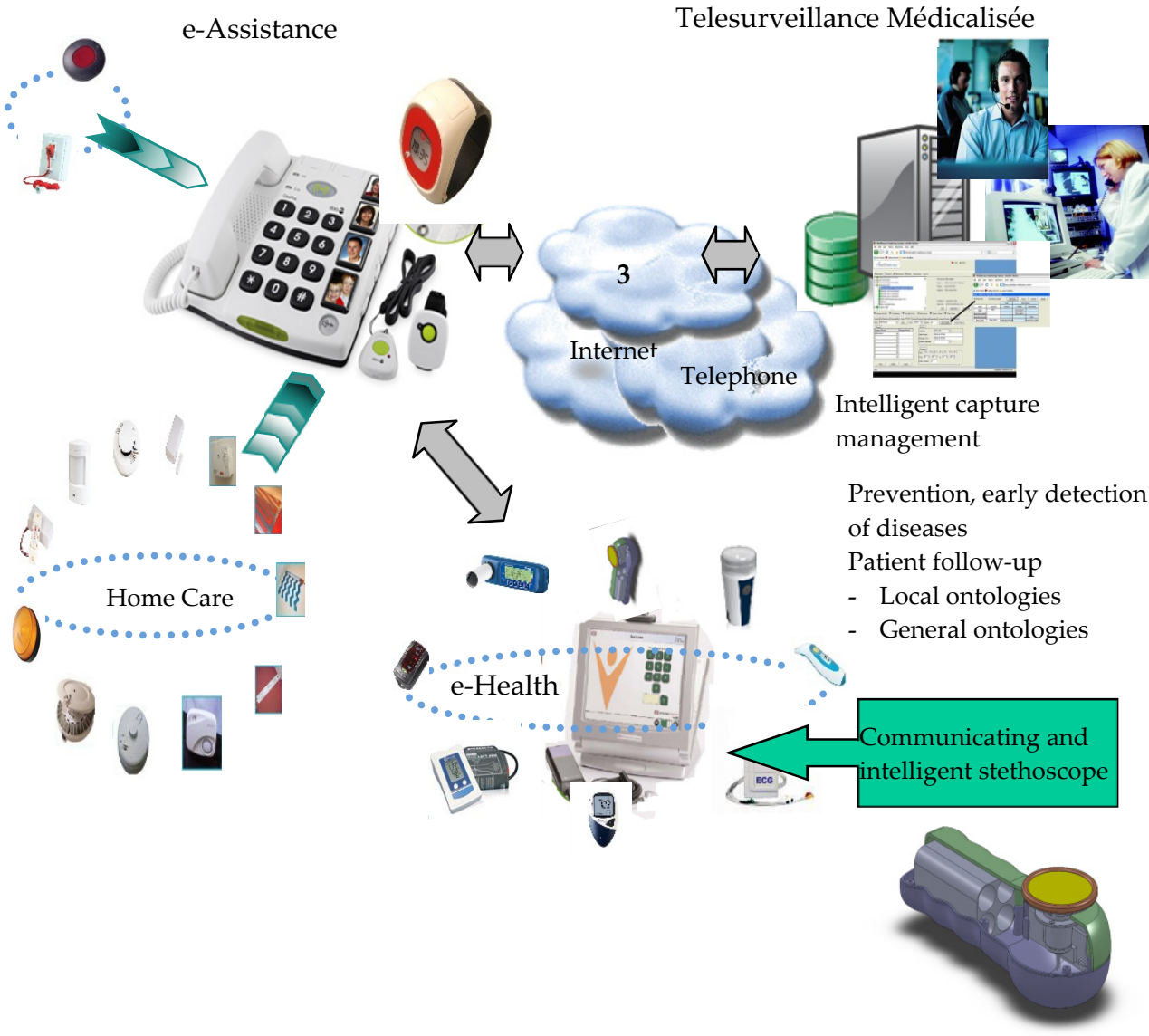

Figure 9. Prototype of a telemedicine platform enabling the "secure" home support of frail subjects and patients with chronic diseases, and integrating a "communicating" and "intelligent" stethoscope (with the permission of INFRAL Company).

\section{Conclusions}

Conventional auscultation is subjective and not easily shared. Modern medical technology allows us to optimize ausculatory findings and hence achieve a correct diagnosis by physically characterizing sounds through recordings, visualization and automated analysis systems. The development and availability of novel tools based on innovations in science and communications technology provide the clinician with an invaluable aid in order to achieve an early objective diagnosis, as well as offering increased sensitivity and reproducibility of auscultatory findings. Such advances have not only led to the development and use of new intelligent communicating stethoscope systems, but they have also significantly contributed to the revival of telemedicine, particularly as a diagnostic and teaching aid, e-teachnig and pedagogy. 


\section{Author details}

Emmanuel Andrès

Department of Internal Medicine B, University Hospital of Strasbourg (HUS), Strasbourg, France

Unit of Human Sounds Analysis, University of Medicine, University of Strasbourg (UdS),

Strasbourg, France

Laboratory of Research in Pedagogy in Human Health University of Strasbourg, Strasbourg, France

\section{References}

[1] Morton E. Tavel has given a good review on cardiac auscultation in the paper of "Cardiac Auscultation: A Glorious Past--And It Does Have a Future!". Circulation 2006; 113:1255-59.

[2] Reichert S, Gass R, Andrès E. Analyse des sons auscultatoires pulmonaires. ITBM-RBM 2007; 28: 169-80.

[3] Sovijarvi. A, Dalmasso, F. Vanderschoot J et al. Definition of terms for applications of respiratory sounds. Eur Respir Rev 2000; 77: 597-610.

[4] Andrès E, Hajjam A. Advances and innovations in the field of auscultation. Health Technol 2012; 2: 5-16.

[5] Andrès E, Reichert S, Gass R, Brandt C. A French national research project to the creation of an auscultation's school: the ASAP project. Eur J Intern Med 2009; 20: 323-7.

[6] Andrès E, Brandt C, Gass R. De l'intérêt de caractériser les sons de l'auscultation pulmonaire à la création d'une école de l'auscultation... Presse Med 2008; 37: 925-7.

[7] Sovijarvi AR, Malmberg LP, Charbonneau G, Vandershoot J. Characteristics of breath sounds and adventitious respiratory sounds. Eur Respir Rev 2000; 10: 591-6.

[8] Sovijarvi A, Vanderschoot J, Earis JE. Standardization of computerised respiratory sound analysis. Eur Respir Rev 2000; 10: 585-91.

[9] Andrès E, Brandt C, Gass R, Reichert S. Nouveaux développements dans le domaine de l'auscultation. Rev Pneumol Clin 2010; 66: 209-13.

[10] Elphick HE, Ritson S, Rodgers H, Everard ML. When a wheeze is not a wheeze: acoustic analysis of breath sounds in infants. Eur Respir J 2000; 16: 593-7.

[11] Kompis M, Pasterkamp H, Wodicka GR. Acoustic imaging of the human chest. Chest 2001; 120: 1309-21.

[12] Sestini P, Renzoni E, Rossi M, Beltrami V, Vagliasindi M. Multimedia presentation of lung sounds as learning aid for medical students. Eur Respir J 1995; 8: 783-8.

[13] Andrès E, Brandt C, Mecili M, Meyer N. Intérêt d'une démarche pédagogique structurée associée à de nouveaux outils de visualisation des signaux auscultatoires dans le cadre de l'apprentissage de la sémiologie auscultatoire: Étude prospective auprès de 30 étudiants du deuxième cycle des études médicales. Pédagogie Med 2012: in press.

[14] Myint WW, Dillard B. An electronic stethoscope with diagnosis capability. Southeastern Symposium on System Theory. Proceedings of the 33rd, pp. 133-137, 2001. 
[15] Charbonneau G, Ademovic E, Cheetham B, Malmberg LP. Basic techniques for respiratory sound analysis. Eur Respir Rev 2000; 10: 625-35.

[16] Earis JE, Cheetham B. Current method used for computerised respiratory sound analysis. Eur Respir Rev 2000; 10: 586-90.

[17] Reichert S, Gass R, Kehayoff Y, Brandt C, Andrès E. Analysis of respiratory sounds: state of the art. Clinical Medicine Circulatory Respiratory Pulmonary Medicine 2008; 2: 4558.

[18] Earis JE, Cheetham BM. Future perspectives for respiratory sound research. Techniques for respiratory sound analysis. Eur Respir Rev 2000; 10: 636-640.

[19] Cheetham B, Charbonneau G, Giordano A, Helisto P, Vanderschoot J. Digitization of data for respiratory sound recordings. Eur Respir Rev 2000; 10: 621-4.

[20] Vannuccini L, Earis JE, Helistö P et al. Capturing and preprocessing of respiratory sounds. Eur Respir Rev 2000; 10: 616-20.

[21] Le Cam S, Salzenstein F, Collet C. Fuzzy pairwise Markov chain to segment correlated noisy data. Signal Processing 2008; 88: 2526-41.

[22] Salzenstein F, Collet C, Le Cam S, Hatt M. Non-stationary fuzzy Markov chain. Pattern Recognition Letters 2007; 28: 2201-08.

[23] Hung K., Luk BL, Choy WH, Tsa BI, Tso SK. Multifunction stethoscope for telemedicine. Medical Devices and Biosensors. 2nd IEEE/EMBS International Summer School on, pp. 87-89, 2004. 